\title{
PID Temperature Controller Design for Shell and Tube Heat Exchanger
}

\author{
Firew D. Olana \\ Mettu University/Department of Electrical and computer Engineering, Mettu, Ethiopia \\ Email: firew.dereje@gmail.com \\ Tadele A. Abose \\ Addis Ababa institute of technology/School of Electrical engineering, Addis Ababa, Ethiopia \\ Email: tadenegn@gmail.com
}

Received: 24 November 2020; Accepted: 14 January 2021; Published: 08 February 2021

\begin{abstract}
Heat exchangers are one of the most important thermal devices. Shell and tube heat exchangers are the common types of heat exchangers and sustained a wide range of operating temperature and pressure. Modeling and controlling heat exchanger system is a difficult assignment because of its nonlinearity. As the flow rates changes, the gain, time delay and time constant varies, hence causing system nonlinearity. The solution for such problems is finding acceptable mathematical model and design a controller which provides better performance indices. In this paper mathematical model (experimental or empirical based) to represent the real system and design suitable controller which remove the offset and settle fast with minimum steady state error has been proposed. To this end, system model design the Proportional-Integral-Derivative controller for shell and tube heat exchanger using Ziegler Nichols method, Cohen-coon method and Chein et al. method. Since two opposing dynamic effects are existing in the system and has a problem of dynamics of inverse response and large overshoot. Therefore, Chein et al. tuning method have better performance than that of the others. In case of Chein et al. the overshoot of $2.577 \%$ and settling time of $63.1 \mathrm{~s}$.
\end{abstract}

Index Terms: Heat exchanger, Ziegler-Nichols, Cohen-coon and Chein et al.

\section{Introduction}

In many engineering processes heat exchangers are important thermal devices, and used to change the temperature distribution of two materials either direct or indirect contacts $[1,2,3]$. There are different types of heat exchangers that can be used in industries but the most commonly used ones are shell and tube heat exchangers. They are applicable for a wide range of operating temperatures and pressures. There are methods of determining a model for a system, namely first principle and empirical models [4]. Empirical modeling provides to handle unmolded dynamics and uncertainties $[4,5,6,7,8]$. The heat exchangers have different gain, time constant and dead time at different range of flow rate, thus, the model of the system is time variant [6]. For such a system, it is better to have a model based on system identification or empirical modeling [9]. The PID controller is the most common control algorithm [10,11,12]. A survey has shown that $90 \%$ of control loops are PI and PID structures [13,14]. The implementation of this form of feedback controller has been widely used in any industrial processes. PID controllers is the combination of three parameters, Proportional gain ( $\left.K_{c}\right)$, integral time $\left(T_{i}\right)$ constant, and derivative time constant $\left(T_{d}\right)$ [13]. More sophisticated tuning method can get rise to considerable improvements in performance, but they are also more demanding computationally and depend on more information of process dynamics [14]. The choice of method should be based on the characteristics of the process and performance requirements. PID controller is applicable in many process control application areas.

This paper addresses: To find a suitable mathematical modeling for shell and tube heat exchanger which has an inverse dynamics and unmolded disturbances through experimental setup. Designing a PID controller of different algorithm for the system, and the best controller has to be recommended based on its system output response performance indices i.e. overshoot, rise time and settling time.

The rest of the paper is organized as follows. Section 2 presents literature review. Section 3 experimental system modeling. Section 4 presents PID controller design. Section 5, result and discussion, and section 6 concludes the paper. 


\section{Literature Review}

In the following literatures, approaches and methodologies, result and discussions, and future works have been concluded.

Authors in [15] explain the application area of heat exchanger and the approach of control strategy as follow in their research entitled "PID control of heat exchanger system". And, they have concluded as follows:

The paper has taken a case study of heat exchanger system and evaluates different methods to control the outlet fluid temperature. Firstly, a classical PID controller has been designed to achieve the control objective. But due to the unsatisfactory performance of the PID controller a feed forward controller has been designed and placed in the forward path of the system. To further increase the efficiency of the system the internal model based PID controller has been designed and implemented. The internal model based PID controller gives satisfactory performance in both steady state and transient state in time domain analysis. The performance indices of all the controllers have been also evaluated. The paper takes the process model to be the same as the process, which is practically impossible to achieve. Implementation of direct model and inverse model-based controller and apply system identification as well as neural networks concepts for estimation of process model has been proposed as a future work.

The authors in [16] have concluded the following points in their research "Temperature Control of Shell and Tube Heat Exchanger by Using Intelligent Controllers-Case Study “.

In this paper, design of a temperature control of a shell and tube heat exchanger based on Neuro -fuzzy PID control has been discussed by comparing it with PID and Fuzzy PID. The analysis of fuzzy controller has been designed in MATLAB. The fuzzy self-tuning PID control system model has also been designed by SIMULINK. The results suggested that self-tuning parameter of fuzzy PID controller has a smaller system overshoot, faster response and less steady state error thereby making it stronger than conventional PID controller. The paper concluded that fuzzy selftuning PID control has better dynamic response and steady state error characteristics.

The authors in [17] have explained the following ideas in their research entitled "Control Strategies of Heat Exchanger".

From the experimental part, it has concluded that the heat exchanger behaves like an integrator dynamic. It represents an unstable process response, which acts similar to ramp input. Any disturbance or set point changed detected in the process will result in gradually decrease or increase of process variable moving towards the set point or away from the set point. Increment in manipulated variable (MV) gives a reverse acting process response while decrement in MV gives a direct acting process response.

The authors in [18] have done the paper entitled "Cascade PID temperature controller for FOPDT model of shell and tube heat exchanger based on Matlab/Simulink". They targeted PID controller tuned using Ziegler Nichols method, and results large over shoot of $36.54 \%$, and rise time of 121.5 second. The author's conclusion reveals that controlling and tuning mechanisms are unsatisfactory. Thus, another tuning method which gives better performance indices is more appealing.

The above researches reveal that the heat exchanger control system is nonlinear by nature, and difficult to control with conventional PID tuning methods. Which in turn results in poor performance indices? The other thing taken in to consideration is most research works of heat exchanger control are used the first principle modeling. Contrastingly, in this thesis the modeling of the system is based on experimental activity, and the controller design is based on recent PID algorithm with proper simulation

\section{Experimental System Modeling}

System modeling has been carried out using the method of empirical modeling (system identification) that handles all operating ranges. Firstly, the partitioning strategy is based on an experimental partitioning that takes all flow rate ranges into account. $[13,14,19]$. The laboratory heat exchanger shown in Fig.1 is designed to demonstrate heat transfer in a shell and tube heat exchanger with seven tubes and three transverse baffles in the shell. In normal operation, the hot fluid flows from the hot water circulator to one end cup of the shell and passes through the bundle of stainless steel tube; the cold fluid flows from the cold water supply through the cylindrical shell. This type of exchanger consists of a nest of parallel tubes enclosed in a cylindrical shell. Heat is transferred between the fluid flowing through the tubes and another fluid flowing through the cylindrical shell around the nest of tubes. A series of baffles inside the shell performs different functions: support the tubes, prevent vibration caused by flow and guide the flow back and forth across the nest of tubes which increases the velocity of the fluid and the beat transfer coefficient. The dimension of the laboratory heat exchanger for this experiment is $1.5 \times 0.7 \times 2 \mathrm{~m}$. This experiment takes $200 \mathrm{~L} / \mathrm{h}$ of cold water or disturbance variable, hot water input as manipulated variable and cold water output as controlled variable. Performing the experiment by applying Binary pseudo random signal in to the manipulated variables i.e. varying the manipulated variable flow rate from $150 \mathrm{~L} / \mathrm{h}$ up to $450 \mathrm{~L} / \mathrm{h}$, in a response recording the output temperature of cold water. Finally, based on input-output data acquired from the experimental test, the system model in equation (1) and (2) has been obtained using system identification. As shown in Fig. 1. It is a laboratory shell and tube heat exchanger plant. 


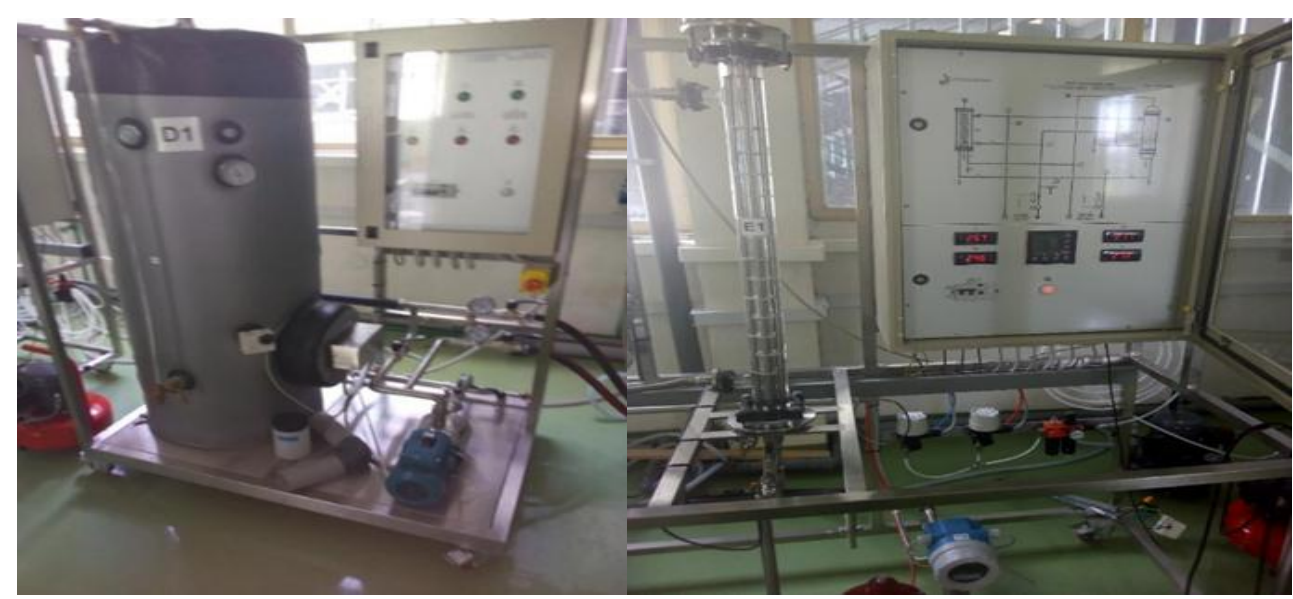

Fig.1. Laboratory Shell and tube heat exchanger plant

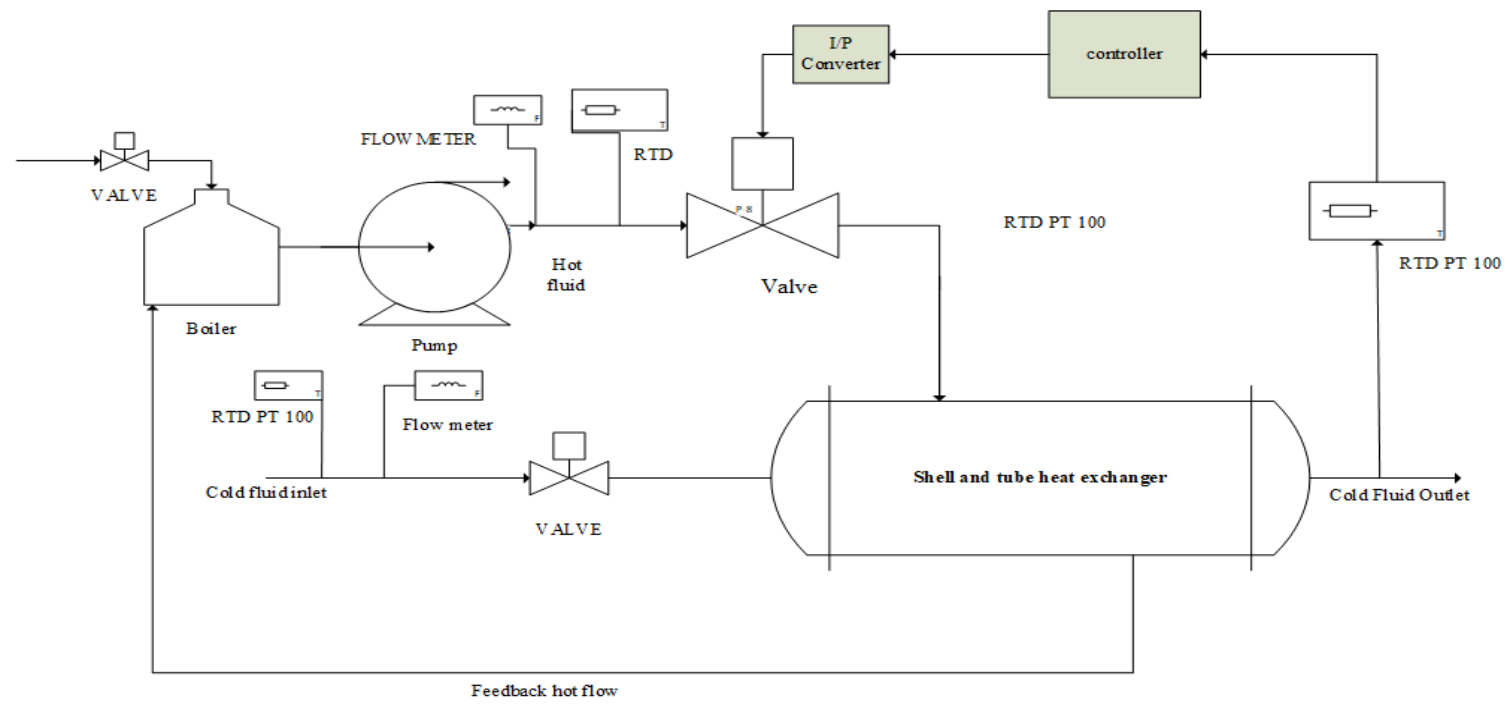

Fig. 2. Overall process control of shell and tube heat exchanger system

Shown in Fig. 3. is a flow chart of system identification that used to find the model of system.

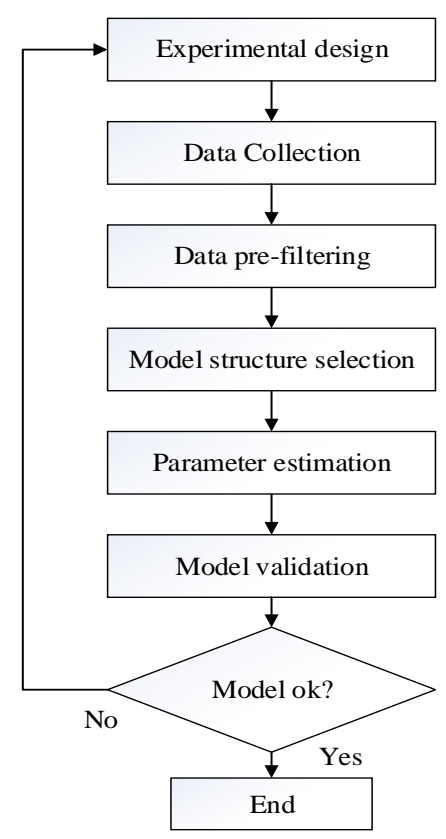

Fig. 3. System identification flow chart 
The system input is assigned with different amplitudes, ranging from $150 \mathrm{~L} / \mathrm{h}$ to $450 \mathrm{~L} / \mathrm{h}$ based on an experimental partitioning strategy. The number of data to be identified is up to 460 with 1 second sampling time. In order to have a disturbance model, apply an input signal through a disturbance variable or change the disturbance variable and record the corresponding controlled variable. The following plant and disturbance transfer function model for shell and tube heat exchanger was obtained using the system identification modeling approach. The experimental design shall be shown in Table 1.

Table 1. System identification experimental specification

\begin{tabular}{|c|c|c|c|c|}
\hline No of Tests & Hot water flow rate(L/h) & $\begin{array}{c}\text { Cold water } \\
\text { flowrate }(\mathrm{L} / \mathrm{h})\end{array}$ & $\begin{array}{c}\text { Hot water } \\
\text { temperature }\left({ }^{\circ} \mathrm{C}\right)\end{array}$ & $\begin{array}{c}\text { Cold water temperature } \\
\left({ }^{\circ} \mathrm{C}\right)\end{array}$ \\
\hline Test One & 150 & 200 & 42 & 28 \\
\hline Test Two & 300 & 200 & 48 & 28 \\
\hline Test three & 450 & 200 & 40 & 28 \\
\hline
\end{tabular}

From the system identification the following process and disturbance model is obtained:

A. Plant Model

$$
\mathrm{G}(\mathrm{s})=\frac{0.23601(1+49.8)}{(1+9.625)(1+567.9 s)} e^{-3.252}
$$

\section{B. Disturbance Model}

$$
G_{d}(s)=\frac{0.00013953(1+0.1772 S)}{(1+0.1745 S)(1+0.2342 S)}
$$

As shown in Fig. 4. and Fig. 5. the open loop system transfer function of the modeled shell and tube heat exchanger with disturbance input and the corresponding system response.

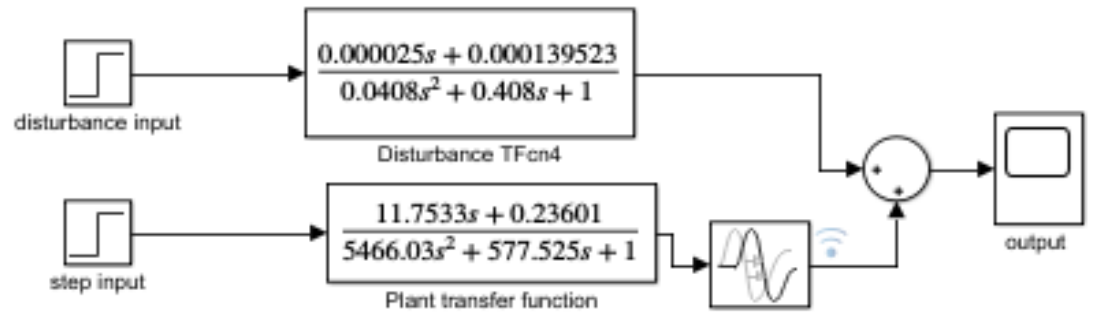

Fig.4. Open loop system transfer function

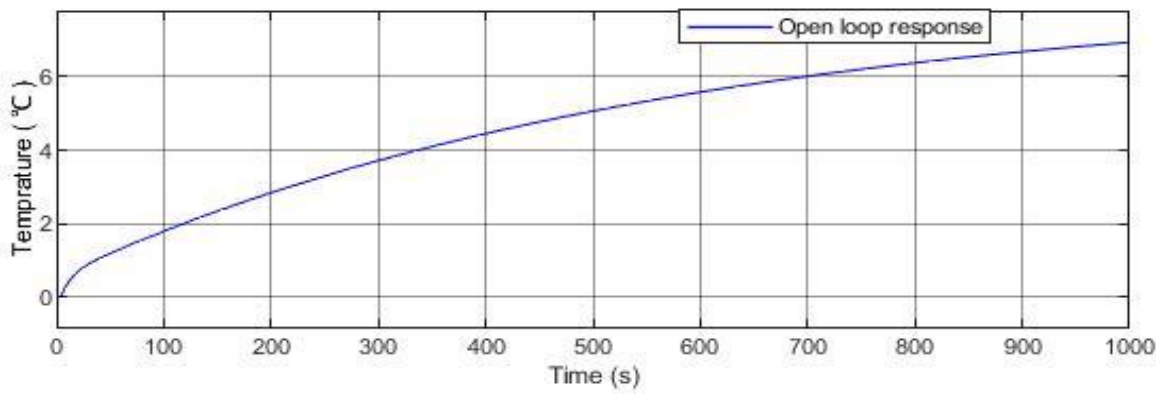

Fig.5. Open loop response of the system

\section{Pid Controller Design}

\section{A. Ziegler-Nichols PID Tuning}

There are two approaches called Ziegler and Nichol's tuning rules which are the first rule and the second rule. Since the Plant model and disturbance model is second order system plus time delay with zero system. Additionally, the plant model does not cross the $\mathrm{j} \omega$-axis. Therefore, it is not possible to design the Ziegler-Nichols second rule tuning [7], 
but it is possible to design the first rule by approximating the FOPDT to the SOPDT model of the plant. Using a firstorder system with a transport delay, the following controller was used as follows:

$$
\frac{G(s)}{U(s)}=\frac{K e^{-L s}}{T_{s}+1}
$$

Table 3. Ziegler- Nichols first rule tuning method

\begin{tabular}{|c|c|c|c|}
\hline Type of controller & $K_{P}$ & $T_{i}$ & $T_{d}$ \\
\hline $\mathrm{P}$ & $\frac{T}{L}$ & $\infty$ & 0 \\
\hline $\mathrm{PI}$ & $0.9 \frac{T}{L}$ & $\frac{L}{0.3}$ & 0 \\
\hline PID & $1.2 \frac{T}{L}$ & $2 L$ & $0.5 L$ \\
\hline
\end{tabular}

The value for $K_{c}=1.2 \frac{T}{L}, T_{i}=2 L$ and $T_{d}=5 L$, the plant model is approximated to first order plus time delay system using Taylor series expansion that have similar dynamic and steady state characteristics with the original model. Then, designing the PID controller with Z-N first order rule.

$$
G(s)=\frac{11.7533+0.23601}{567.9 s+1} e^{-12.877 s}
$$

The PID parameters have been developed from the design. The value of $K_{c}$ is $52.922, T_{i}$ is 2.05 , and $T_{d}$ value is 340.08 .

\section{B. Cohen-Coon PID tuning method}

The method developed by Cohen and Coon (1953) is based on a first-order plus time-delay process model. A set of tuning parameters was empirically developed to yield a closed-loop response with a quarter decay ratio. The main design requirement is the rejection of load disturbances [7]. The approximated plant model shown as follows and design the controller using Cohen-coon method.

$$
\frac{C(s)}{U(s)}=\frac{K_{P} e^{-\theta S}}{\tau_{p S}+1}
$$

Table 4. Cohen-coon tuning method

\begin{tabular}{|c|c|c|c|}
\hline Type of controller & $K_{c}$ & $T_{i}$ & $T_{d}$ \\
\hline $\mathrm{P}$ & $\frac{\tau_{p}}{k_{P} \theta}\left[1+\frac{\theta}{3 \tau_{p}}\right]$ & $\infty$ & 0 \\
\hline $\mathrm{PI}$ & $\frac{\tau_{p}}{k_{P} \theta}\left[0.9+\frac{\theta}{12 \tau_{p}}\right]$ & $\frac{\theta\left[30+\frac{3 \theta}{\tau_{p}}\right]}{9+\frac{20 \theta}{\tau_{p}}}$ & 0 \\
\hline PID & $\frac{\tau_{p}}{k_{P} \theta}\left[\frac{4}{3}+\frac{\theta}{4 \tau_{p}}\right]$ & $\theta\left[32+\frac{6 \theta}{\tau_{p}}\right]$ & $\frac{4 \theta}{13+\frac{8 \theta}{\tau_{p}}}$ \\
\hline
\end{tabular}

The value for 


$$
K_{c}=\frac{\tau_{p}}{k_{p} \theta}\left[\frac{4}{3}+\frac{\theta}{4 \tau_{p}}\right] T_{i}=\frac{\theta\left[32+\frac{6 \theta}{\tau_{p}}\right]}{13+\frac{8 \theta}{\tau_{p}}}, T_{d}=\frac{4 \theta}{11+\frac{2 \theta}{\tau_{p}}}
$$

The plant transfer function is represented as followed

$$
G(s)=\frac{11.7533 S+0.23601}{567.9 S+1} e^{-12.877 s}
$$

The PID parameters have been developed from the design. The value of $K_{c}$ is $254.4, T_{i}$ is 8.1 , and $T_{d}$ is 1185.5 .

\section{Chein et al. PID tuning method}

The controller design is based on a process model. The system which have inverse response plus dead time, and large overshoot plus dead time is much more difficult to control than the usual first-order, second order, or integrating plus dead time systems [20, 21, 22]. The following is Chein et al. PID tuning method.

$$
G c(S)=K c\left(1+\frac{1}{T i S}+\frac{T_{d} S}{1+\frac{T_{d}}{N} S}\right)
$$

PID controller tuning for second order plus time delay with zero model is:

$$
G(s)=\frac{\mathrm{K}_{m}\left(T_{m 3} \mathrm{~S}+1\right) e^{-s \tau_{m}}}{\left(1+T_{m 1} S\right)+\left(1+T_{m 2} S\right)} \operatorname{or} G(s)=\frac{\mathrm{K}_{m}\left(T_{m 3} \mathrm{~S}+1\right) e^{-s \tau_{m}}}{T_{m 1} S^{2}+2 \xi T_{m 1} S+1}
$$

Table 5. Chein et al PID tuning rule for second order system plus delay (SOSPD)

$$
\begin{array}{c|c|c|}
\hline K_{c} & T_{i} & T_{d} \\
\hline \frac{0.829 \xi T_{m 1}}{\mathrm{~K}_{m} \tau_{m}} & 2 \xi T_{m 1}-T_{m 1} & 1 T_{d} \\
1 T d=\frac{T m_{1}{ }^{2}}{2 \xi T m_{1}-T m_{3}}-T m_{3} \\
N=\frac{T m_{1}}{T m_{3}\left(2 \xi T m_{1}-T m_{3}\right)}-1
\end{array}
$$

The identified plant model of shell and tube heat exchanger is:

$$
G(s)=\frac{0.23601(1+49.8 S)}{(1+9.625 S)(1+567.9 S)} e^{-3.252 s}
$$

The PID parameters have been developed based on Chein et al. tuning mechanisms. The value of $K_{p}$ is 311.43 , $T_{i}$ is $502.72, T_{d}$ value is -38.9 and filter value $(\mathrm{N})$ of -0.997 .

\section{Results and Discussions}

\section{A. Ziegler-Nichols PID Tuning}

The performance indices of the controller are simulated in the MATLAB/Simulink simulation environment. Step input test signals have been used, and the results are illustrated in Fig. 6. The advantage of Ziegler and Nichols first 
method is that the tuning rule is very simple to use. Disadvantages are: Further fine tuning is needed, controller settings are aggressive, resulting in large overshoot and oscillatory responses, poor performance for processes with a dominant delay, closed loop very sensitive to parameter variations and Parameters of the step response may be hard to determine due to measurement noise.

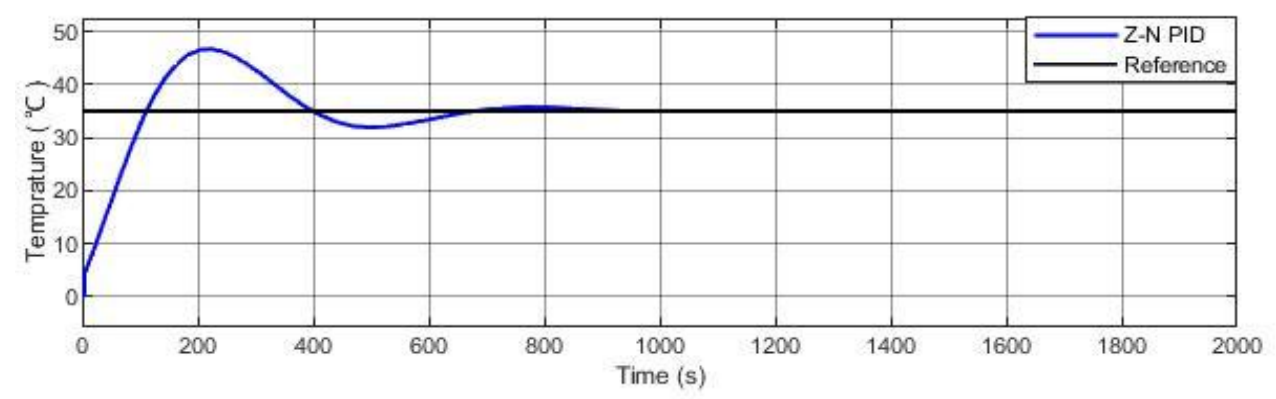

Fig. 6. Output Signal of Ziegler-Nichols PID with Step input

Fig. 6 demonstrates the response of Z-N PID controller with respect to step input. The response performance indices with rise time of 93 second, settling time of 287 second, and overshoot of $34.5 \%$.

\section{B. Cohen-Coon PID tuning}

Cohen-coon PID tuning is implemented in the MATLAB with step input reference signal. The performance indices of this controller illustrated in Fig. 7. The main design requirement is the rejection of load disturbances. A major problem with the Cohen-Coon parameters is that they tend not to be very robust; that is, a small change in the process parameters can cause the closed-loop system to become unstable.

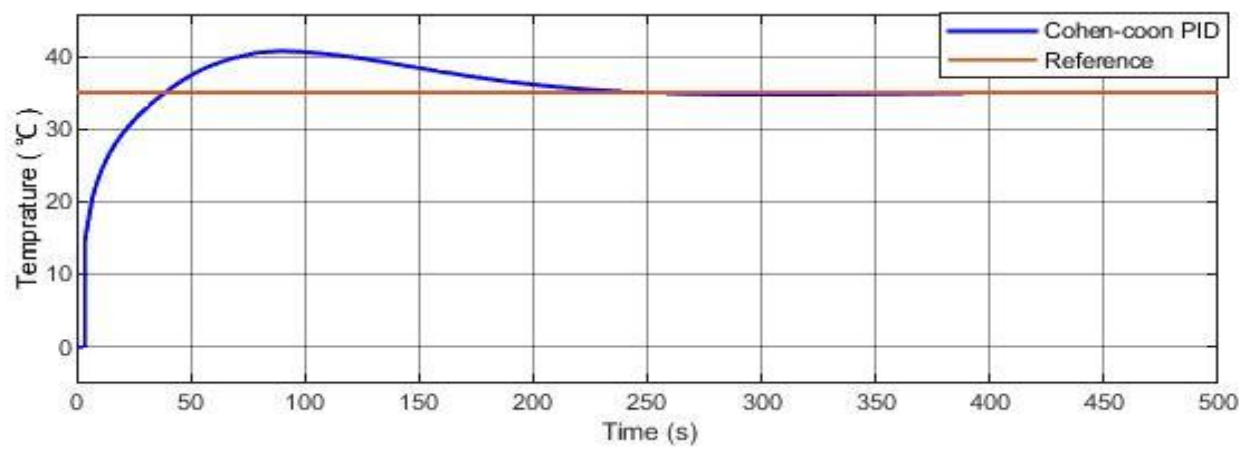

Fig. 7. Output Signal of Cohen-coon PID with Step input

From Fig. 7 it can be observed that the response of Cohen-coon PID controller with step input. The results from the responses are overshoot of $17 \%$, rise time of 22 second, and settling time of 90 second.

\section{Chein et al. PID tuning}

Chein et al. tuning system the best tuning system for process models which has large overshoot plus dead time process, because the controller overcome the inverse response plus time delay and large overshoot systems. Chein et al. PID tuning is implemented in the MATLAB with step input reference signal. The performance indices of this controller illustrated in Fig. 8. In Chein et al. tuning method both inverse response plus dead time and large overshoot response plus dead time with denominator dynamics of an underdamped nature will be treated. 


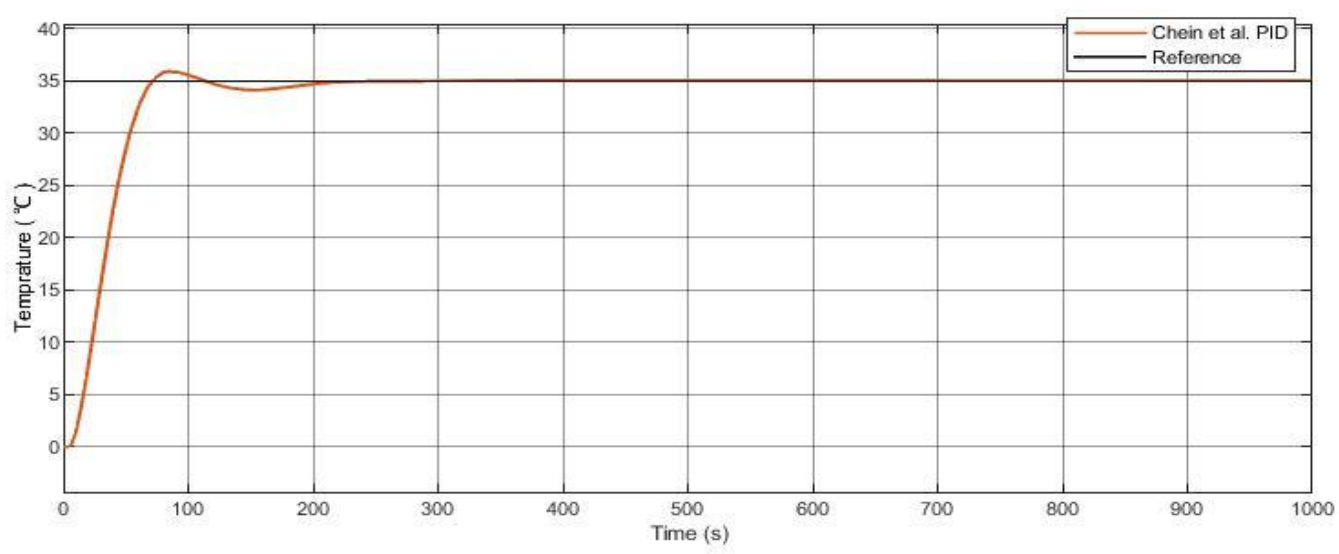

Fig. 8. Output Signal of Chein et al. PID with Step input

Fig. 8. Demonstrate the response of Chein et al. PID controller with step input. The results from the responses are overshoot of $2.577 \%$, rise time of $43.6 \mathrm{~s}$, and settling time of 63.1 second. The responses are relatively better that others.

\section{Comparison of the Results}

Fig.9 shows a comparison of the step response performances of the demonstrated controllers. In case of ZieglerNichols PID tuning the overshot of $34.5 \%$, rise time of 93 second and settling time of 287 second, this result shows that more time to track the desired value. And the Cohen-coon PID tuning overshoot of $17 \%$, rise time of 22 second and settling time of 90 second, relatively Cohen-coon is better performance indices than Z-N PID. It can be observed that Chein et al. PID controller have better performance in terms of speed of response and overshoot than Z-N PID and Cohen-coon PID controller.

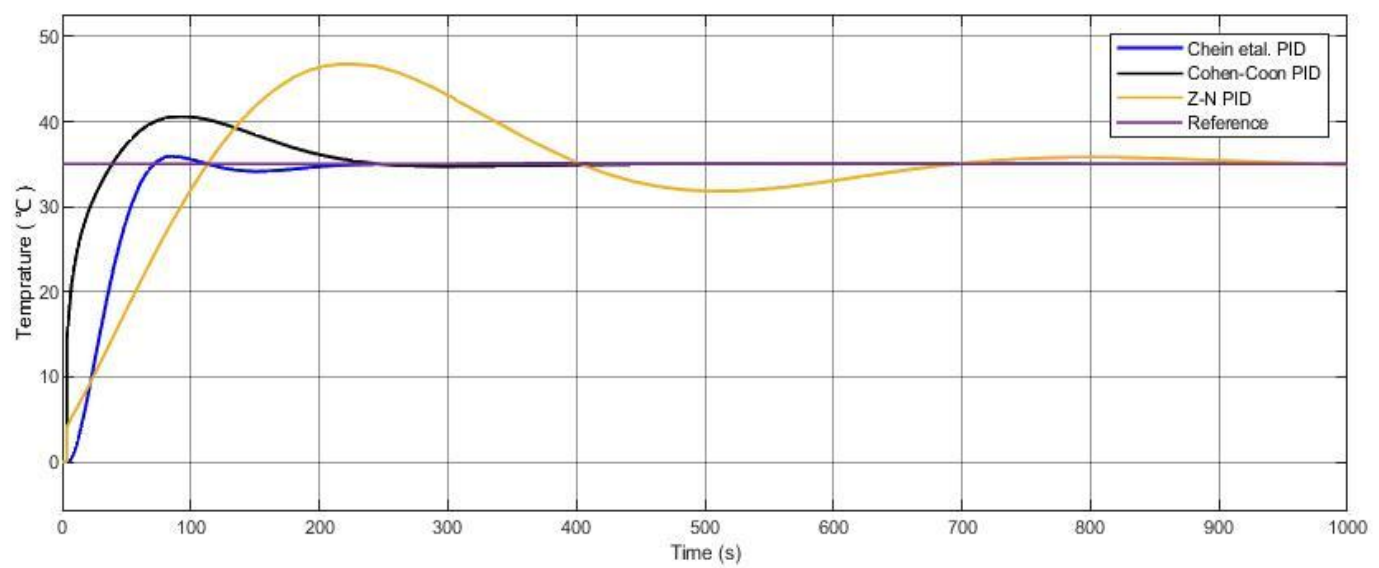

Fig. 9. Comparison of demonstrated controller's performance

\section{Conclusions}

Process control application needs to have more accurate plant model and acceptable controller design that can be characterized by less overshoot, rise time and settling time. Specifically, critical process control application required accurate plant modeling and controller design. Modeling and controlling heat exchanger is very challenging task due to its nonlinearity. The solution for such a system is finding mathematical model that represents real and designing better controller which remove the offset and settle fast.

In this paper, laboratory heat exchanger has been used, and the model of the system obtained experimentally using system identification. Process model and disturbance model has been developed by system identification. The system has high overshoot and large settling time naturally. Since three types of PID controller has been designed in order to get better performance indices. From the result it observed that Z-N tuning method and Cohen-coon method is less performance indices than that of Chein et al. PID controller. In case Chein et al. PID the overshoot of $2.577 \%$ and settling time of 63.1 second. The Chein et al method has high tends to overcome large system overshoot and settling time for such a system. 


\section{References}

[1] S. Nithya et al.," Predictive Controller Design for A Shell and Tube Heat Exchanger," IEEE- ICAESM, 2007, PP1075-1080.

[2] A. Vasickaninova and M. Bakosova," Robust Controller Design for a Heat Exchanger," International Conference on Process Control, IEEE, Kottayam, India, 2016, PP. 113-118.

[3] Kuppan Thulukkanam, Heat Exchanger Design Handbook, Second edition, CRC Press, New York, USA, 2013.

[4] Arun K. Tangirala, Principles of System Identification Theory and Practice, CRC Press, Taylor and Francis Group, Boca Raton, New York, USA, 2015.

[5] Vinaya Krishna V, K. Ramkumar and V. Alagesan," Control of Heat Exchangers Using Model Predictive Controller," International Conference On Advances in Engineering, Science and Management, IEEE, Nagapattinam, Tamil Nadu, India, 2012, PP. 242-246.

[6] Shanu Khan, Modeling and Controlling Heat Exchanger Process, Hamirpur, National institute of technology, Lambert Academic publishing, Saarbrucken, Germany, 2017.

[7] B. Wayne Bequette, Process Control Modeling, Design, and Simulation, Prentice, NJ, USA, 2002

[8] Sami El Ferik and Ahmed A. Adeniran," Modeling and Identification of Nonlinear Systems: A Review of the Multimodel Approach-Part 1," IEEE Transactions on Systems, Man, And Cybernetics Systems, 2017, V. 47, PP. 2168-2216.

[9] Farzin Piltan, Shahnaz TayebiHaghighi, Nasri B. Sulaiman,"Comparative Study between ARX and ARMAX System Identification", International Journal of Intelligent Systems and Applications (IJISA), Vol.9, No.2, pp.25-34, 2017. DOI: 10.5815/ijisa.2017.02.04

[10] Munna Kumar, Ram Sharan Singh, "PID Controller Design for SOPDT using Direct Synthesis Method", International Journal of Intelligent Systems and Applications(IJISA), Vol.11, No.9, pp.56-64, 2019. DOI: 10.5815/ijisa.2019.09.06

[11] RamaKoteswara Rao Alla, Lekyasri N, Rajani K," PID Control Design for Second Order Systems", International Journal of Engineering and Manufacturing(IJEM), Vol.9, No.4, pp.45-56, 2019.DOI: 10.5815/ijem.2019.04.04

[12] Thanet Ketthong, Satean Tunyasirut, Deacha Puangdownreong, "Design and Implementation of I-PD Controller for DC Motor Speed Control System by Adaptive Tabu Search", International Journal of Intelligent Systems and Applications(IJISA), Vol.9, No.9, pp.69-78, 2017. DOI: 10.5815/ijisa.2017.09.08

[13] Control Design Approach Based on Multi-Linear Models, Proceedings of the American Control Conference, Albuquerque, New Mexico June, 3490-3494, (1997).

[14] Mohammad Ali, Nekoui Seyed and Mohammad Sajadi, "Nonlinear System Identification using Locally Linear Model Tree and Particle Swarm Optimization," IEEE international conference on industrial technology, Mumbai, India, 1563-1568, (2006).

[15] Yuvraj Bhushan Khare and Yaduvir Sing, "PID Control of Heat Exchanger System," International Journal of Computer Applications, volume 8, October, 2010, PP 22-27.

[16] Mr.P. Sivakumar, Dr.D. Prabhakaran and Dr.T. Kannadasan," Temperature Control of Shell and Tube Heat Exchanger by Using Intelligent Controllers-Case Study," International Journal of Computational Engineering Research, Vol. 2, Issue. 8, 2012, PP 285-292.

[17] Nasser M. Ramli and Haslinda Zabiri," Control Strategies of Heat Exchanger," International Journal of Engineering Sciences \& Research Technology, ISSN: 2277-9655, February, 2017.

[18] Erik Tridianto et al," Cascaded PID Temperature Controller for FOPDT Model of Shell and Tube Heat Exchanger Based on Matlab/Simulink," International Electronics Symposium on Engineering Technology and Applications, Surabaya, Indonesia, 2017, PP. 185-191.

[19] Shinichi Imai and Toru Yamamoto," Design and Experiment of a IMC-Based PID Controller using Multiple Local Linear Models," IEEE international conference on emerging technologies and factory automation (ETFA), 6505-6509, (2017).

[20] Aidan O'Dwyer, Hand Book of PI and PID Controller Tuning Rules, Dublin Institute of Technology, Ireland, Imperial College Press, London, (2009).

[21] Kiam Heong Ang and Gregory Chong, "PID Control System Analysis, Design, and Technology," IEEE Transactions on Control Systems Technology, V.13, 559-576 (2005).

[22] Chien et al.," Simple PID Controller Tuning Method for Processes with Inverse Response Plus Dead Time or Large Overshoot Response Plus Dead Time," Industrial and engineering chemistry research, V. 42, 4461-4477, (2003)

\section{Authors' Profiles}

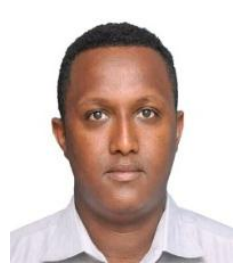

Firew Dereje has received BSC degrees from Hawassa University, Ethiopia by Electrical and computer Engineering in 2013 and MSC degrees from Addis Ababa Science and Technology University, Ethiopia by Electrical Engineering (Control and instrumentation Engineering Specialization) in 2019. He is currently lecturer and Head of Electrical and Computer Engineering in Mettu University, Ethiopia, under College of Engineering and Technology. He has publication on ICAST 2019 and different international journals. His research interests are backhaul networks, power reliability, power quality, Controller Design, and IOT. 


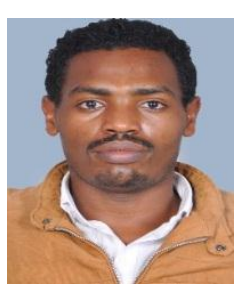

Tadele Abera has received BSC degrees from Hawassa University, Ethiopia by Electrical Engineering in 2011 and MSC degrees from Addis Ababa University, Ethiopia by Electrical Engineering (Communication Engineering Specialization) in 2014. He was test and commissioning Engineer in different electric power upgrading projects in Ethiopia. He is currently University lecturer in Ethiopia, under School of Electrical and Computer Engineering. He has publications on ICAST 2019 and different international journals. His research interests are cognitive radio, massive MIMO, millimeter wave communication, backhaul networks and interference management techniques. His research interest extends to power systems and control including power reliability, power quality, PID controllers and MPC.

How to cite this paper: Firew D. Olana, Tadele A. Abose, " PID Temperature Controller Design for Shell and Tube Heat Exchanger ", International Journal of Engineering and Manufacturing (IJEM), Vol.11, No.1, pp. 37-46, 2021. DOI: 10.5815/ijem.2021.01.05 